\title{
EVALUASI TINGKAT ADOPSI KLON UNGGUL DI TINGKAT PETANI KARET PROPINSI SUMATERA SELATAN
}

\author{
Evaluation of Adoption Level of High Yielding Clones at \\ Rubber Smallholder in South Sumatera Province \\ Lina Fatayati SYARIFA ${ }^{11}$, Dwi Shinta AGUSTINA ${ }^{1)}$, Cicilia NANCY ${ }^{11}$, \\ dan Muhammad SUPRIADI ${ }^{2)}$ \\ ${ }^{11}$ Balai Penelitian Sembawa, Pusat Penelitian Karet, Jl. Raya Palembang - P. Balai KM 29 \\ ${ }^{21}$ Pusat Penelitian Karet, Jalan Salak No 1 Bogor 16151
}

Diterima tanggal 14 Maret 2012 / Disetujui tanggal 16 Juli 2012

\begin{abstract}
Despite the rapid increase of total natural rubber export of South Sumatera, the classic problem still heard is the low productivity of smallholder rubber. It is caused by several factors, mainly the low use of rubber clones at smallholder level viz. around $40 \%$. Various strategic benefits have been obtained from the former rubber development projects. Therefore, it is needed to analize the know-how and adoption levels of rubber smallholders towards advanced rubber technologies, especially the use of high rubber yielding clones. The research aimed to identify the adoption level of high yielding clones based on type of clone at rubber smallholder level. This study was conducted by survey method. Selection of location was carried out purposively by selecting the central areas of rubber. Data was collected by Focus Group Discussion (FGD) method involving village officers, followed by interviewing farmers. The survey results showed that the rate of rubber clones adoption in sampling areas in South Sumatera had reached $59.2 \%$ of the average existing rubber areas. In planting year of 2010, the rate of clone adoption reached $67 \%$ of the average self-help planting per year. It was noted that clones of PB 260 were the most widely known and adopted by smallholders (83\%).
\end{abstract}

Keywords: Hevea brasiliensis, high yielding clones, clone adoption, rubber smallholders

\section{Abstrak}

Sekalipun total ekspor karet alam Sumatera Selatan meningkat pesat, permasalahan klasik yang masih sering terdengar bahwa produktivitas di perkebunan rakyat masih rendah. Rendahnya produktivitas perkebunan karet di Indonesia dipengaruhi beberapa faktor, diantaranya adalah tingkat penggunaan bibit karet klonal di tingkat petani karet yang masih rendah $( \pm 40 \%)$. Berbagai manfaat strategis telah diperoleh dari adanya proyek-proyek pengembangan karet rakyat terdahulu, karena itu perlu dianalisis mengenai seberapa besar perkembangan pengetahuan dan adopsi petani terhadap teknologi karet maju khususnya penggunaan klon karet unggul. Penelitian ini bertujuan untuk mengetahui tingkat adopsi klon unggul berdasarkan jenis klon. Penelitian dilakukan dengan metode survei dengan memilih sampel secara purposive, yaitu daerahdaerah yang merupakan sentra karet. Pengambilan data dilakukan melalui metode Focus Group Discussion (FGD) yang melibatkan perangkat-perangkat desa dan diikuti wawancara dengan petani. Hasil survei menunjukkan bahwa tingkat adopsi klon karet pada daerah-daerah yang dijadikan sampel di Sumatera Selatan telah mencapai $59,2 \%$ dari rata-rata areal tanaman karet yang ada. Pada tahun tanam 2010, tingkat adopsi klon mencapai $67 \%$ dari rata-rata penanaman swadaya per tahun. Jenis klon yang paling banyak dikenal dan diminati oleh petani adalah PB 260 (83\%).

Kata kunci : Hevea brasiliensis, klon unggul, adopsi klon, petani karet

\section{PENDAHULUAN}

Karet merupakan komoditas penting di Indonesia, karena arealnya yang cukup luas mencapai 3,4 juta ha, dan menjadi sumber mata pencaharian bagi sekitar dua juta 
keluarga. Pada tahun 2009 ekspor karet alam Indonesia mencapai 2,3 juta ton $(6,02$ miliar US\$) (Ditjenbun, 2009). Sejak tahun 2002, terjadi kecenderungan kenaikan harga karet alam dunia yang cukup tinggi hingga saat ini (Gambar 1). Diperkirakan kenaikan harga karet ini akan berlangsung lama karena adanya pertumbuhan ekonomi negara-negara di dunia, peningkatan permintaan karet alam dan peningkatan harga karet sintetis. Kondisi ini menyebabkan komoditas karet ke depan menjadi lebih prospektif.

Konsumsi karet alam dalam jangka panjang diperkirakan akan terus meningkat sejalan dengan pertumbuhan perekonomian dunia dan meningkatnya standar hidup manusia. Pertumbuhan perekonomian dunia yang pesat di China, India, Korea Selatan, dan Brazil pada sepuluh tahun terakhir, telah memberi dampak pertumbuhan permintaan karet alam yang cukup tinggi. Smit (2003) memprediksi bahwa pertumbuhan konsumsi karet alam ke depan akan terus meningkat melampaui tingkat pertumbuhan produksi. Diperkirakan permintaan karet alam pada tahun 2035 akan mencapai sekitar 15 juta ton, sedangkan pertumbuhan produksi akan stabil pada sekitar $2 \%$ per tahun, sehingga produksi karet alam dunia tahun 2035 hanya mencapai sekitar 13,6 juta ton. Berarti akan terjadi kekurangan pasokan karet alam untuk memenuhi kebutuhan konsumsi dunia.

Dengan demikian Indonesia memiliki peluang untuk menjadi produsen terbesar dunia. Indonesia memiliki keunggulan komparatif dan kompetitif yang lebih baik dibandingkan dengan negara-negara pesaing seperti Thailand dan Malaysia, karena Indonesia masih memiliki lahan yang lebih luas dan tenaga kerja yang lebih murah untuk mendukung pembangunan kebun karet. Untuk mencapai hal itu diperlukan upaya-upaya untuk mempercepat peningkatan produktivitas karet alam di Indonesia, khususnya di Propinsi Sumatera Selatan.

Propinsi Sumatera Selatan sebagai satu sentra karet terbesar memiliki luas areal karet sekitar 1 juta ha dengan produktivitas sebesar $981 \mathrm{~kg} / \mathrm{ha} / \mathrm{th}$. Luasan tersebut didominasi oleh perkebunan rakyat yaitu mencapai 94\% yang sebagian besar merupakan areal karet swadaya. Karet juga menjadi sumber mata pencaharian lebih dari 750 ribu keluarga petani di Sumatera Selatan (Ditjenbun, 2009). Pada tahun 2009 komoditas karet masih tetap menjadi penyumbang devisa terbesar ekspor nonmigas di Sumatera Selatan dengan jumlah ekspor mencapai 696 ribu ton atau senilai 1,11 miliar US\$, sedangkan total ekspor tahun 2010 meningkat 12,5\% atau

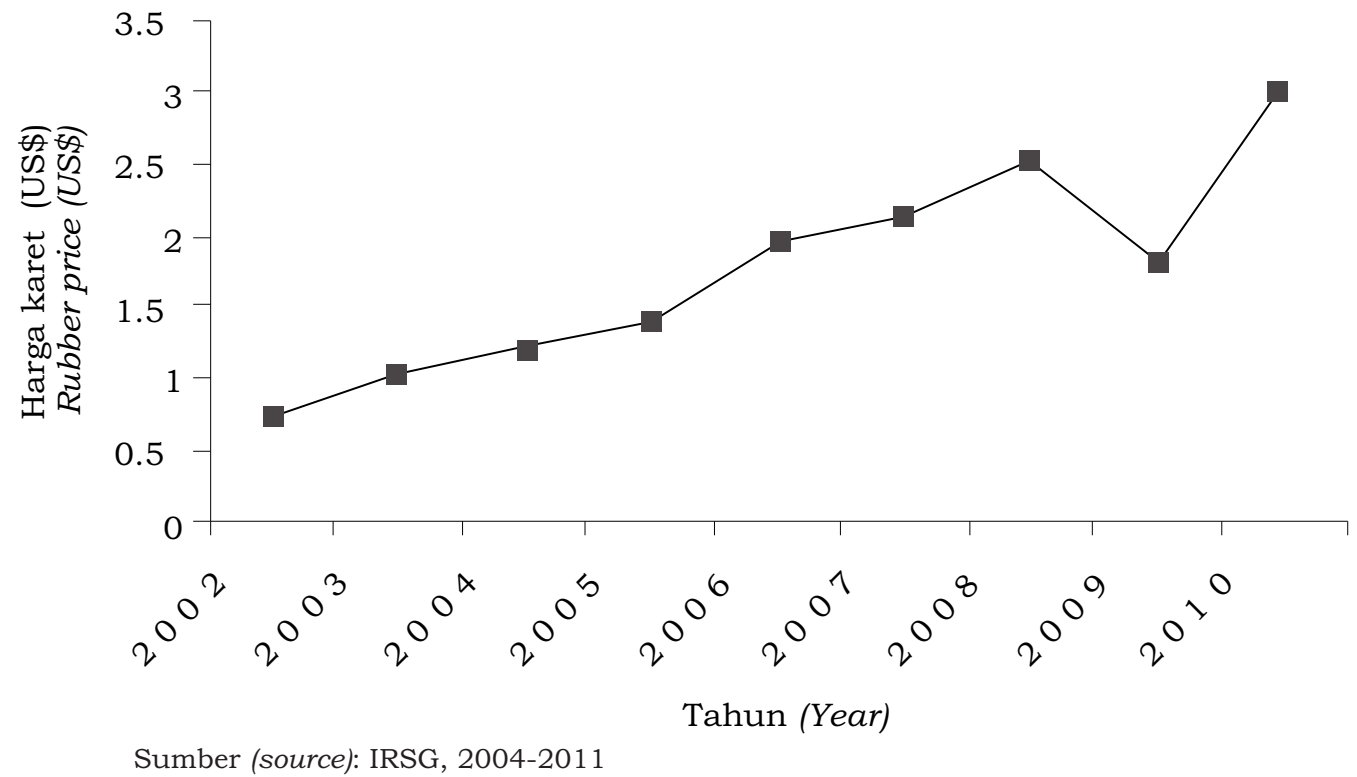

Gambar 1. Grafik harga karet SIR 20

Figure 1. SIR 20 price graph 
tercatat sebanyak 756 ribu ton (Dinas Perindustrian dan Perdagangan Sumatera Selatan, 2010).

Sekalipun total ekspor Sumatera Selatan meningkat demikian pesat, permasalahan klasik yang masih sering terdengar bahwa produktivitas di perkebunan rakyat masih rendah. Rendahnya produktivitas perkebunan karet di Indonesia disebabkan beberapa faktor antara lain masih luasnya areal karet tua yang perlu segera diremajakan ( $>100$ ribu ha) (Ditjenbun, 2009), tingkat penggunaan bibit klonal di tingkat petani yang masih rendah $( \pm 40 \%)$ serta belum adanya penerapan standar budidaya dan pemeliharaan kebun karet yang sesuai anjuran di tingkat petani (Hendratno dan Supriadi, 2011).

Mengingat upaya perbaikan dan peningkatan produktivitas karet telah banyak dilakukan oleh pemerintah dan telah berlangsung cukup lama sejak tahun 1980an melalui proyek-proyek pengembangan karet rakyat, diperkirakan berbagai manfaat strategis telah diperoleh dari adanya proyek-proyek tersebut. Dari tahun 1982-2009 di Sumatera Selatan telah terjadi peningkatan total luas areal sebesar 2,62\% per tahun (Tabel 1).

Dari peningkatan areal tersebut, terjadi juga peningkatan produktivitas sebesar 3,80\% per tahun (Dinas Perkebunan Sumsel, 2008) atau 3,53\% per tahun (Gapkindo Sumsel, 2008). Peningkatan luas areal dan produktivitas ini merupakan hasil dari berbagai upaya yang dilakukan oleh pemerintah melalui proyek-proyek berbantuan, kemitraan dengan instansiinstansi terkait maupun swadaya petani sendiri. Karena itu, perlu dianalisis seberapa besar tingkat pengetahuan dan adopsi petani terhadap teknologi karet khususnya penggunaan bibit karet unggul dalam perannya meningkatkan produktivitas karet di Sumatera Selatan.

\section{BAHAN DAN METODE}

Penelitian dilakukan pada bulan September-Desember 2011 dengan menggunakan metode survei. Kegiatan dilakukan dengan memilih sampel secara purposive, yaitu pada tahap pertama dipilih kabupaten yang dinilai merupakan daerah sentra karet dan potensial untuk pengembangan karet ke depan, dilanjutkan dengan pemilihan kecamatan. Pada kecamatan tersebut contoh desa diambil secara purposive dengan kriteria merupakan desa penghasil karet dan masih memiliki potensi untuk pengembangan karet. Di tingkat desa pengambilan data dilakukan melalui metode Focus Group Discussion (FGD) yang melibatkan perangkat-perangkat desa (Sekdes, BPD atau Kelompok Tani), dilanjutkan wawancara dengan petani karet. Survei dilakukan di 9 kabupaten/kota, 45 kecamatan, dan 85 desa seperti tertera pada Tabel 2 .

Tabel 1. Produktivitas karet di Sumatera Selatan, 1982-2008

Table 1. Rubber productivity in South Sumatera, 1982-2008

\begin{tabular}{|c|c|c|c|c|}
\hline $\begin{array}{c}\text { Uraian } \\
\text { Description }\end{array}$ & $\begin{array}{l}\text { Sumber } \\
\text { Source }\end{array}$ & 1982 & 2008 & $\begin{array}{c}\text { Rata-rata pertumbuhan/th } \\
\text { Average growth/yr } \\
(\%)\end{array}$ \\
\hline Luas total (ha) & & 474,851 & 965,756 & 2,62 \\
\hline Luas TM (ha) & & 277,054 & 598,501 & 2,82 \\
\hline \multirow{2}{*}{$\begin{array}{l}\text { Produksi } \\
\text { (ton karet } \\
\text { kering) }\end{array}$} & Disbun & 125,077 & 797,925 & 5,61 \\
\hline & Gapkindo & 112,904 & 659,000 & 5,44 \\
\hline \multirow{2}{*}{$\begin{array}{l}\text { Produktivitas } \\
\text { (kg/ha/th) }\end{array}$} & Disbun & 452 & 1,333 & 3,80 \\
\hline & Gapkindo & 408 & 1,101 & 3,53 \\
\hline
\end{tabular}

Sumber (Source) : Dinas Perkebunan Sumsel dan Gapkindo, 2008 


\section{HASIL DAN PEMBAHASAN}

Kajian sosial ekonomi dilakukan dalam rangka untuk mengevaluasi tingkat pengetahuan dan adopsi petani terhadap

Tabel 2. Wilayah sampel yang terpilih dalam penelitian

Table 2. Sample areas selected for the study

\begin{tabular}{|c|c|c|}
\hline $\begin{array}{l}\text { Kabupaten } \\
\text { Regency }\end{array}$ & $\begin{array}{l}\text { Kecamatan } \\
\text { Sub-district }\end{array}$ & $\begin{array}{c}\text { Jumlah desa } \\
\text { Villages }\end{array}$ \\
\hline Musi Banyuasin & $\begin{array}{l}\text { Babat Supat } \\
\text { Bayung Lencir } \\
\text { Batanghari Leko } \\
\text { Lais } \\
\text { Tungkal Ilir } \\
\text { Sanga Desa }\end{array}$ & 11 \\
\hline Musi Rawas & $\begin{array}{l}\text { Muara Kelingi } \\
\text { Tuah Negeri } \\
\text { BTS Ulu } \\
\text { Muara Beliti } \\
\text { Tiang P. Kepungut } \\
\text { Karang Dapo } \\
\text { STL Ulu Terawas } \\
\text { Rawas Ulu }\end{array}$ & 12 \\
\hline $\begin{array}{l}\text { Lubuk Linggau } \\
\text { Muara Enim }\end{array}$ & $\begin{array}{l}\text { LLG. Selatan } \\
\text { Gunung Megang } \\
\text { Lubai } \\
\text { Rambang } \\
\text { Sungai Rotan } \\
\text { Gelumbang } \\
\text { Abab } \\
\text { Penukal } \\
\text { Talang Ubi } \\
\text { Tanah Abang }\end{array}$ & $\begin{array}{c}2 \\
15\end{array}$ \\
\hline Banyuasin & $\begin{array}{l}\text { Betung } \\
\text { Banyuasin III } \\
\text { Sembawa } \\
\text { Rambutan }\end{array}$ & 14 \\
\hline OKI & $\begin{array}{l}\text { Lempuing Jaya } \\
\text { Pangkalan lampam } \\
\text { Pampangan } \\
\text { Pedamaran Timur }\end{array}$ & 6 \\
\hline $\begin{array}{l}\text { Ogan Ilir } \\
\text { OKU Induk }\end{array}$ & $\begin{array}{l}\text { Payaraman } \\
\text { Semidang Aji } \\
\text { Lubuk Raja } \\
\text { Peninjauan } \\
\text { Lubuk Batang } \\
\text { Lengkiti } \\
\text { Sosoh Buay Rayap }\end{array}$ & $\begin{array}{c}3 \\
11\end{array}$ \\
\hline OKU Timur & $\begin{array}{l}\text { BP Peliung } \\
\text { BP Bangsa Raja } \\
\text { Belitang Madang } \\
\text { Raya } \\
\text { Belitang III } \\
\text { Belitang Jaya } \\
\text { Semendawai Barat }\end{array}$ & 11 \\
\hline $\begin{array}{l}\text { Total } 9 \\
\text { Kabupaten }\end{array}$ & 45 Kecamatan & 85 Desa \\
\hline
\end{tabular}

teknologi karet khususnya mengenai klon karet unggul di wilayah-wilayah sentra karet di Propinsi Sumatera Selatan. Hasil survei menunjukkan bahwa tingkat adopsi klon karet di desa contoh rata-rata sebesar 59\% dari total, dengan tingkat adopsi klon karet yang paling tinggi terdapat di wilayah Kabupaten Muara Enim (83\%), disusul Kabupaten Banyuasin (81\%), dan OKU Timur (75\%) (Tabel 3).

Data pada Tabel 4 juga menunjukkan bahwa setiap tahun telah terjadi penanaman karet secara swadaya oleh petani. Hal ini menunjukkan bahwa petani karet di Sumatera Selatan tidak hanya mengandalkan penanaman karet melalui bantuan proyek. Pada tahun 2010, tercatat rata-rata penanaman karet secara swadaya per tahun di Sumatera Selatan mencapai 47,2 ha per desa. Dari luasan tersebut rata-rata tingkat adopsi klon karet pada tahun tanam 2010 di desa-desa contoh Sumatera Selatan telah mencapai $67 \%$, dengan tingkat adopsi klon karet yang paling tinggi terdapat di Kabupaten Muara Enim yaitu sebesar 91,3\% diikuti oleh Kabupaten Banyuasin, Musi Banyuasin, OKU Timur, Ogan Komering Ilir, Ogan Ilir dan OKU Induk.

Tingginya tingkat adopsi klon oleh petani di Kabupaten Muara Enim disebabkan dampak adanya proyek-proyek berbantuan yang dimulai sejak awal Pelita I melalui UPP berbantuan (SRDP dan TCSDP) dan PIR. Proyek-proyek tersebut telah meningkatkan pengetahuan petani terhadap keunggulan bibit karet klonal, sehingga pada perkembangannya berdampak pada penanaman karet swadaya oleh petani dengan menggunakan bibit klonal, Kemudian Pemda Kabupaten Muara Enim, terus melanjutkan upaya peremajaan karet melalui Proyek Gerbang Serasan, dan bantuan bibit APBD. Besarnya dampak adopsi klon karet unggul yang disebabkan oleh proyek-proyek berbantuan tersebut juga terjadi di kabupaten-kabupaten lain seperti Kabupaten Banyuasin, OKU Timur, dan Ogan Ilir.

Kabupaten Banyuasin dengan tingkat adopsi klon karet sebesar $81 \%$ dari rata-rata total areal karet seluas 1856 ha per desa, merupakan daerah pengembangan proyekproyek SRDP, PIR, dan PRPTE. Dampak adanya proyek-proyek tersebut telah mengakibatkan tingginya penanaman 
Tabel 3. Adopsi klon karet pada kabupaten-kabupaten di Sumatra Selatan Table 3. Adoption of rubber clones in regencies of South Sumatera

\begin{tabular}{|c|c|c|c|c|}
\hline $\begin{array}{l}\text { Kabupaten } \\
\text { Regency }\end{array}$ & $\begin{array}{l}\text { Luas areal } \\
\text { karet } \\
\text { Rubber } \\
\text { area, } \\
\text { (ha) }\end{array}$ & $\begin{array}{l}\text { Luas areal } \\
\text { proyek } \\
\text { Project area } \\
\text { (ha) }\end{array}$ & $\begin{array}{l}\text { Jenis proyek } \\
\text { Types of project }\end{array}$ & $\begin{array}{l}\text { Adopsi klon } \\
\text { keseluruhan } \\
\text { Total clone } \\
\text { adoption } \\
(\%)\end{array}$ \\
\hline Musi Banyuasin & 1315 & 44 & $\begin{array}{c}\text { CSR } \\
\text { SRDP, Partisipatif, APBD, }\end{array}$ & $85^{*}$ \\
\hline Musi Rawas & 2536 & 130 & HTR & 29 \\
\hline Lubuk Linggau & 400 & 75 & $\begin{array}{c}\text { APBD, SRDP } \\
\text { Gerbang Serasan, PIR, }\end{array}$ & 19 \\
\hline Muara Enim & 1916 & 311 & APBD & 83 \\
\hline Banyuasin & 1856 & 271 & SRDP, PIR, PRPTE, APBD & 81 \\
\hline OKI & 1216 & 44 & APBD & 51 \\
\hline Ogan Ilir & 1242 & 262 & $\begin{array}{c}\text { APBD, SRDP } \\
\text { Partisipatif, APBD, PRPTE, }\end{array}$ & 73 \\
\hline OKU Induk & 2230 & 161 & Grant, TCSDP, & 63 \\
\hline OKU Timur & 677 & 150 & $\begin{array}{c}\text { APBD, SRDP, Partisipatif, } \\
\text { Revitbun }\end{array}$ & 75 \\
\hline $\begin{array}{l}\text { Rata-rata Sumatera Selatan } \\
\text { Average South Sumatera }\end{array}$ & 1487 & 161 & & 59 \\
\hline
\end{tabular}

* = Tingkat adopsi tahun tanam 2010 (Year of planting adoption level 2010)

Sumber (Source) : Data primer (Primary data)

Tabel 4. Perkembangan adopsi klon karet secara swadaya di tingkat petani pada tahun tahun 2010

Table 4. Development of rubber clone adoption by self-help farmers in planting 2010

\begin{tabular}{llccc} 
No. & $\begin{array}{c}\text { Kabupaten } \\
\text { Regency }\end{array}$ & $\begin{array}{c}\text { Adopsi klon } \\
\text { Clone adoption } \\
(\%)\end{array}$ & $\begin{array}{c}\text { Luas penanaman } \\
\text { swadaya/th } \\
\text { Self-help } \\
\text { planting area/yr }\end{array}$ & $\begin{array}{c}\text { Adopsi klon 2010 } \\
\text { Adoption clone 2010 } \\
\text { (\%) }\end{array}$ \\
\hline 1. & Muara Enim & 83,3 & 37,4 & 91,3 \\
2. & Banyuasin & 80,8 & 17,5 & 89,6 \\
3. & Musi Banyuasin & NA & 73,8 & 84,7 \\
4. & OKU Timur & 74,7 & 26,5 & 73,0 \\
5. & OKI & 51,3 & 36,3 & 72,0 \\
6. & Ogan Ilir & 73,0 & 75,0 & 70,0 \\
7. & OKU Induk & 63,3 & 45,2 & 62,0 \\
8. & Musi Rawas & 28,6 & 83,1 & 45,4 \\
9. & Lubuk Linggau & 18,5 & 30,0 & 12,5 \\
\multicolumn{2}{c}{ Sumatera Selatan } & 59,2 & 47,2 & 66,7 \\
\hline
\end{tabular}

Sumber (Source): Data Primer (Prrimary data) 
swadaya karet dengan menggunakan klon unggul yang dilakukan secara swadaya. Selain itu, dampak adanya perkebunanperkebunan besar karet dan sentra-sentra pembibitan bibit unggul yang terdapat di wilayah Kabupaten Banyuasin juga telah banyak memberikan pengaruh yang signifikan terhadap perkembangan tingkat adopsi klon, sehingga pada tahun tanam 2010, tingkat adopsi klon di Kabupaten Banyuasin telah mencapai $89,6 \%$ dari ratarata penanaman swadaya seluas 17,5 ha per desa per tahun.

Sementara tingkat adopsi klon karet di Kabupaten Musi Banyuasin pada tahun tanam 2010 mencapai $84,7 \%$ dari rata-rata penanaman swadaya seluas 74 ha per desa per tahun. Kondisi tersebut juga merupakan dampak dari adanya proyek pengembangan karet dan perkebunan besar.

Kabupaten OKU Timur merupakan daerah pengembangan karet yang baru. Awalnya petani di Kabupaten OKU Timur merupakan petani padi sawah. Namun dampak dari peningkatan harga karet sejak tahun 2002, telah menyebabkan minat masyarakat beralih ke pengembangan karet. Program penanaman karet di wilayah ini sebagian besar berupa bantuan bibit unggul dari dana APBD. Saat memulai usahatani karet, sebagian besar petani hanya mengandalkan bantuan bibit APBD, sehingga tanaman karet yang ditanam umumnya bibit klonal. Karena itu tingkat adopsi klon unggul keseluruhan di Kabupaten OKU Timur tercatat mencapai $74,7 \%$ dari rata-rata total areal karet seluas 677 ha per desa. Selain bantuan proyek petani juga menanam bibit unggul secara swadaya. Sumber bibit klonal sebagian besar diperoleh petani dari kelompok pembibitan binaan Dinas Perkebunan OKU Timur yang terletak di Martapura, dan kelompok pembibitan binaan Balai Penelitian Sembawa di Belitang.

Dalam perkembangannya, tingkat adopsi klon unggul secara swadaya di Kabupaten OKU Timur menurun. Pada tahun tanam 2010, tingkat adopsi klon karet menurun menjadi $73 \%$ dari rata-rata areal penanaman swadaya per tahun. Hal ini disebabkan adanya kekecewaan petani terhadap produksi yang dihasilkan oleh bibit bantuan yang mereka terima. Petani beranggapan bahwa bibit klonal hasilnya tidak lebih baik daripada bibit seedling yang harganya murah dan mudah diperoleh, sehingga mereka banyak beralih minat menanam karet seedling. Saat ini telah banyak beredar di masyarakat bibit dalam bentuk biji karet yang dikemas dalam kotak dengan merk dagang Golden Hope atau yang sering disebut petani dengan istilah "polong merah" atau "balam merah", karena penampilan permukaan biji tersebut berwarna kemerahan. Harga benih tersebut bervariasi antara Rp 200.000,- s/d Rp 400.000,- per kotak (@200 butir/kotak).Benih tersebut telah dipromosikan penjualnya sebagai bibit unggul berasal dari Malaysia, yang tidak perlu diokulasi tetapi akan menghasilkan produksi yang sama dengan bibit unggul. Promosi tersebut berhasil membuat sebagian petani mencoba menanamnya.

Selain bibit Golden Hope, saat ini di OKU Timur telah banyak beredar bibit seedling kaki tiga. Sebelumnya sudah pernah berkembang bibit kaki tiga (three in one) okulasi yang berasal dari Jambi. Namun pada saat ini mulai beredar di masyarakat bibit kaki tiga yang tidak diokulasi. Usaha pembibitan bibit kaki tiga yang tidak diokulasi banyak terdapat di desa Tanjung Batu Kabupaten Ogan Ilir. Harga bibit tersebut di tingkat petani berkisar Rp 3.500,- Rp 5.000,- per polibeg.

Di Kabupaten Ogan Ilir, tingkat adopsi klon keseluruhan mencapai $73 \%$, yang merupakan dampak dari adanya proyek bantuan bibit APBD dari Pemda Ogan Ilir. Namun pada tahun tanam 2010, tingkat adopsi klon menurun menjadi $70 \%$, disebabkan petani mulai banyak yang berminat menanam bibit-bibit seedling yang beredar seperti Golden Hope dan bibit kaki tiga yang tidak diokulasi.

Hal yang sama terjadi di Kabupaten OKU Induk, yang mana tingkat adopsi keseluruhan mencapai 63,3\% dari rata-rata seluruh areal karet per desa. Penggunaan bibit unggul di kabupaten ini dimulai sejak adanya proyek-proyek pembangunan kebun karet seperti SRDP, PRPTE, PIR, dan proyek partisipatif. Selanjutnya, proyek bantuan pembangunan karet diteruskan oleh pemerintah daerah melalui proyek APBD yang berupa bantuan bibit kepada petani. Namun pada tahun tanam 2010, tingkat 
adopsi klon menurun menjadi $62 \%$ dari ratarata luas penanaman karet swadaya, karena petani mulai banyak menanam bibit Golden Hope.

Selanjutnya di Kabupaten Ogan Komering Ilir (OKI) tingkat adopsi klon karet keseluruhan mencapai sebesar 51,3\%. Dalam perkembangannya di tahun tanam 2010, tingkat adopsi klon meningkat menjadi $72 \%$ dari rata-rata penanaman karet per desa. Peningkatan penggunaan klon disebabkan adanya bantuan proyek Pemda melalui APBD memberikan bantuan bibit klonal ke petani.

Wilayah yang memiliki tingkat adopsi klon karet terendah adalah Kabupaten Musi Rawas dan Kota Lubuk Linggau. Dari hasil survei, tingkat adopsi klon dari keseluruhan areal karet di desa-desa contoh Kabupaten Musi Rawas hanya sekitar 28,6\% dari total rata-rata areal karet yang luasnya 2536 ha per desa. Pada tahun tanam 2010, tingkat adopsi klon mencapai sebesar 45,4\% dari rata-rata penanaman karet swadaya per desa. Sementara di Kota Lubuk Linggau, tingkat adopsi klon karet hanya sekitar $18,5 \%$ dari total areal karet yang ditanam per desa. Selanjutnya pada tahun tanam 2010, tingkat adopsi klon hanya sekitar $12,5 \%$ dari rata-rata penanaman karet swadaya yang luasnya 30 ha per desa per tahun. Di wilayah ini, tingkat pengetahuan dan kesadaran petani untuk mengadopsi bibit unggul masih sangat rendah. Meskipun Kota Lubuk Linggau merupakan sentra pembibitan karet terbesar di Sumatera Selatan, dan juga pernah diberikan bantuan proyek peremajaan karet baik melalui SRDP, maupun proyek partisipatif dan bantuan APBD, hal ini tidak memberikan pengaruh yang signifikan terhadap kemajuan tingkat adopsi klon unggul di kedua wilayah ini. Bahkan masih banyak petani yang sama sekali tidak mengenal satupun jenis klon karet unggul yang direkomendasikan.

Di kedua wilayah ini, umumnya petani biasa mengenal dan menggunakan bahan tanam karet seedling berupa cabutan yang dibeli di kalangan-kalangan desa. Selain itu, petani juga sudah banyak yang mengenal dan mengadopsi bahan tanam biji Golden Hope dan Bridgestone. Awalnya kondisi tersebut terjadi selain disebabkan rendahnya pengetahuan dan kesadaran petani dalam mengadopsi bibit unggul, juga disebabkan mahalnya harga bibit karet, dan adanya kekecewaan para petani terhadap produksi bibit okulasi palsu yang tidak memberikan produksi seperti yang diharapkan. Pada Gambar 2 dan Gambar 3 terlihat bahan tanam karet seedling yang banyak beredar dan ditanam oleh petani karet di Sumatera Selatan.

Hasil survei menunjukkan bahwa dari tingkat pengetahuan petani karet di Sumatera Selatan terhadap jenis bibit unggul, yang paling banyak dikenal dan diminati oleh petani adalah jenis PB 260 (83\%), selanjutnya klon GT 1 (48\%), BPM 24 (39\%), IRR 39 (32\%), PR Series (23\%), RRIC 100 (11\%), dan RRIM 600 (Tabel 5). Klon PB 260 banyak dikenal dan diminati petani karena jumlah produksinya tinggi, dan klon PB 260 paling banyak dijumpai di penangkar bibit. Klon GT 1 umumnya dikenal oleh petani-petani yang berada disekitar proyekproyek peremajaan berbantuan (SRDP, TCSDP, dan PIR). Klon GT 1 masih sangat diminati oleh petani karena produksinya yang tinggi dan dianggap klon yang paling tahan terhadap penyakit jamur akar putih. Klon BPM 24 dan seri PR juga banyak diminati petani dikarenakan produksinya yang cukup tinggi. Namun ketersediaannya tidak begitu banyak di penangkar. Klon IRR 39 yang dulunya paling banyak diminati masyarakat petani dikarenakan keunikannya berdaun lima telah membuat petani kecewa. Hal ini dikarenakan sifat klon yang merupakan bahan tanam slow starter, tetapi memberikan produksi yang tidak sesuai dengan harapan petani pada awal sadap. Disarankan untuk lebih banyak memperkenalkan jenis klon unggul yang baru selain PB 260, yang memiliki produksi tinggi kepada para penangkar dan petani, seperti klon IRR 118, IRR 112 dan lainnya.

Data pada Tabel 6 menunjukkan tingkat adopsi budidaya karet meliputi jarak tanam, pemupukan, pengendalian hama, pengendalian penyakit, dan pengendalian gulma. Umumnya petani karet di Sumatera Selatan sudah menggunakan jarak tanam (93\%). Jarak tanam yang biasa dipakai masih rapat yaitu $5 \times 3,4 \times 4$, dan $3 \times 4$. Di Kabupaten Musi Rawas dan Kota Lubuk Linggau masih terdapat petani yang belum menggunakan jarak tanam. 

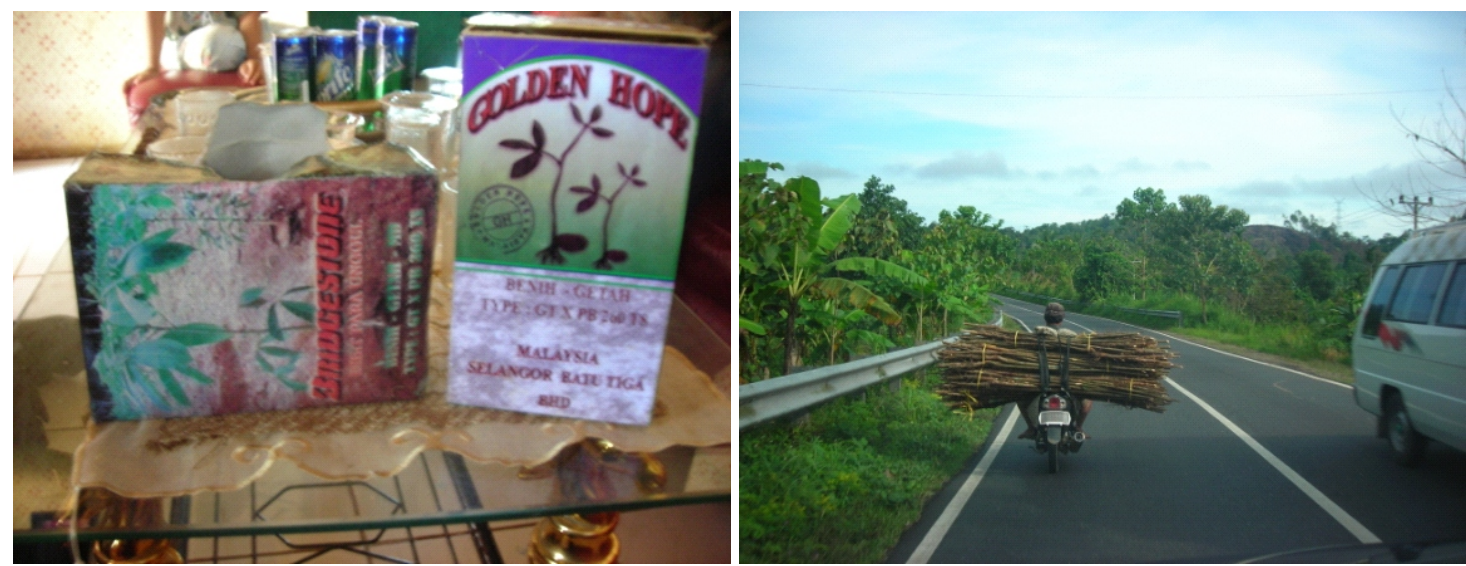

Gambar 2. Biji Golden Hope dan Brigestone (kiri) serta bahan tanam cabutan (kanan) Figure 2. Seeds called Golden Hope and "Brigestone" (left) and rubber seedling (right)

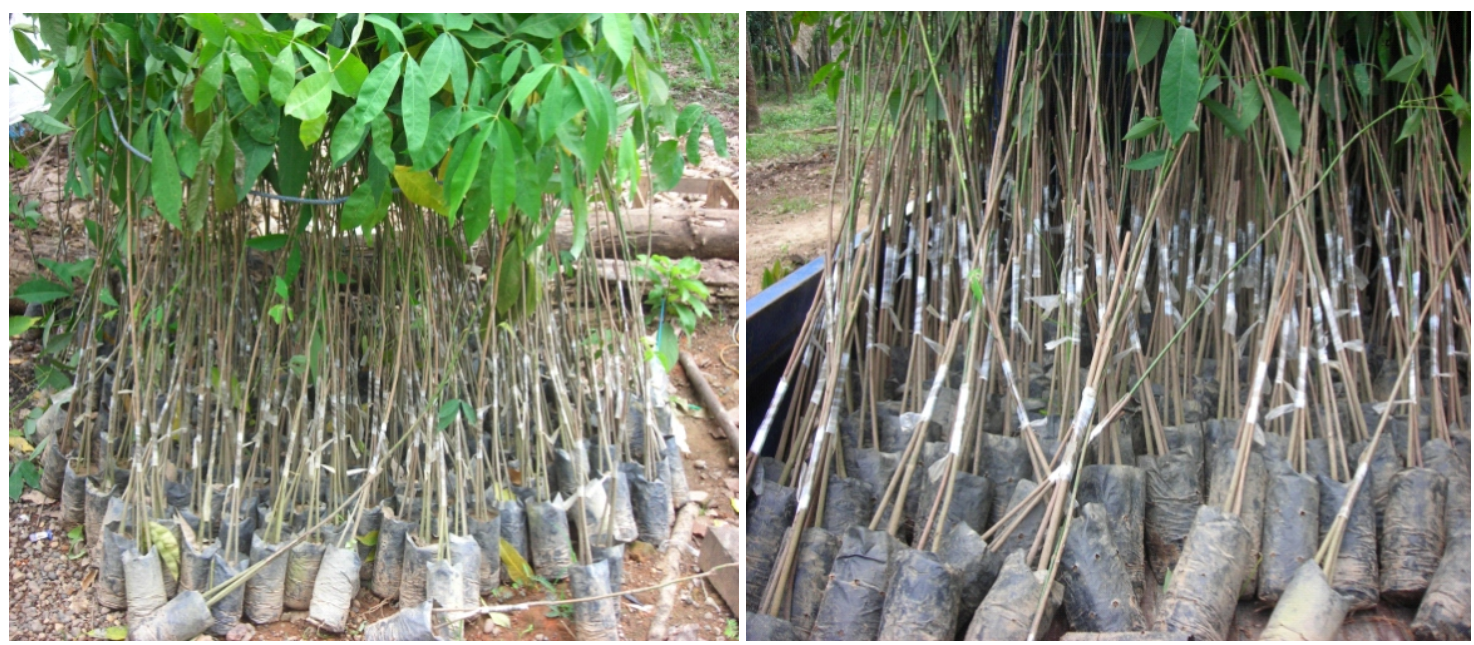

Gambar 3. Bahan tanam asal bibit kaki tiga yang tidak diokulasi

Figure 3. Planting material of ungrafted three-in-one seed

Tabel 5. Tingkat pengetahuan petani terhadap jenis klon Table 5. Farmers know-how about rubber clones

\begin{tabular}{lccccccc}
\hline $\begin{array}{c}\text { Kabupaten } \\
\text { Regency }\end{array}$ & $\begin{array}{c}\text { PB 260 } \\
(\%)\end{array}$ & $\begin{array}{c}\text { GT 1 } \\
(\%)\end{array}$ & $\begin{array}{c}\text { BPM 24 } \\
(\%)\end{array}$ & $\begin{array}{c}\text { IRR 39 } \\
(\%)\end{array}$ & $\begin{array}{c}\text { PR } \\
\text { Series } \\
(\%)\end{array}$ & $\begin{array}{c}\text { RRIC } \\
100 \\
(\%)\end{array}$ & $\begin{array}{c}\text { Lainnya } \\
\text { Others } \\
(\%)\end{array}$ \\
\hline Musi Banyuasin & 100 & 17 & 25 & 5 & 0 & 17 & \\
Musi Rawas & 81 & 51 & 23 & 35 & 25 & 19 & \\
L. Linggau & 50 & 50 & 50 & 50 & 0 & 30 & \\
Muara Enim & 90 & 33 & 30 & 10 & 40 & 10 & \\
Banyuasin & 100 & 66 & 75 & 50 & 0 & 0 & RRIM 600 \\
OKU Induk & 77 & 83 & 43 & 38 & 60 & 0 & \\
OKU Timur & 83 & 33 & 25 & 33 & 33 & 0 & \\
Sumatera Selatan & 83 & 48 & 39 & 32 & 23 & 11 & \\
\hline
\end{tabular}

Sumber (Source) : Data Primer (Primary data) 
Tabel 6. Tingkat adopsi budidaya karet di tingkat petani karet Table 6. Percentage of technical practice at farmer level

\begin{tabular}{|c|c|c|c|c|c|}
\hline $\begin{array}{c}\text { Kabupaten } \\
\text { Regency }\end{array}$ & $\begin{array}{c}\text { Jarak tanam } \\
\text { Plant spacing } \\
(\%)\end{array}$ & $\begin{array}{l}\text { Pemupukan } \\
\text { Fertilization } \\
\text { (\%) }\end{array}$ & $\begin{array}{l}\text { Pengendalian } \\
\text { hama } \\
\text { Pest control } \\
(\%)\end{array}$ & $\begin{array}{l}\text { Pengendalian } \\
\text { penyakit } \\
\text { Disease } \\
\text { control } \\
(\%)\end{array}$ & $\begin{array}{l}\text { Pengendalian } \\
\text { gulma } \\
\text { Weed control } \\
\text { (\%) }\end{array}$ \\
\hline Muara Enim & 100 & 82 & 89 & 29 & 80 \\
\hline Banyuasin & 100 & 96 & 90 & 57 & 96 \\
\hline Musi Banyuasin & 100 & 94 & 100 & 12 & 100 \\
\hline OKU Timur & 100 & 96 & 25 & 25 & 84 \\
\hline OKI & 100 & 94 & 100 & 100 & 13 \\
\hline OKU Induk & 100 & 78 & 17 & 17 & 83 \\
\hline Musi Rawas & 87 & 28 & 88 & 15 & 51 \\
\hline Lubuk Linggau & 54 & 25 & 75 & 0 & 45 \\
\hline Sumatra Selatan & 93 & 77 & 76 & 39 & 65 \\
\hline
\end{tabular}

Sumbe (Source) : Data Primer (Primary data)

Tingkat kesadaran petani dalam penggunaan pupuk di Sumatera Selatan sudah cukup tinggi yaitu mencapai $77 \%$. Tingkat adopsi pupuk paling tinggi di tingkat petani yang berada di Kabupaten Banyuasin, OKU Timur, Musi Banyuasin, OKI, Muara Enim, dan OKU Induk. Umumnya petani melakukan pemupukan 1-2 kali per tahun. Di Kabupaten Musi Rawas dan Lubuk Linggau tingkat penggunaan pupuk masih sangat rendah.

Selanjutnya, tingkat adopsi pengendalian hama di tingkat petani Sumatera Selatan juga cukup tinggi, yaitu $76 \%$. Hama yang biasa terdapat di kebun karet petani adalah babi, monyet, kambing, dan sapi. Untuk mengendalikannya, kebun dijaga dan dipagar. Sementara, tingkat pengen-dalian penyakit di tingkat petani masih sangat rendah $(39 \%)$. Hal ini disebabkan rendahnya pengetahuan petani terhadap pengenalan gejala serangan dan upaya pengendalian penyakit. Tingkat adopsi pengendalian gulma di tingkat petani hanya mencapai 65\%. Di Kabupaten OKI, Lubuk Linggau, dan Musi Rawas masih banyak petani yang membiarkan kebunnya kotor, dan tidak terawat. Permasalahan cara penyadapan masih banyak dijumpai di daerah-daerah yang di survei seperti di Kabupaten Musi Rawas, Lubuk Linggau, dan OKU Timur. Di wilayah-wilayah tersebut masih banyak terjadi kesalahan cara penyadapan (Gambar 4). Karena itu, masih sangat diperlukan penyuluhan serta bimbingan teknis dalam upaya pengendalian penyakit karet, dan teknik penyadapan karet yang sesuai rekomendasi.

\section{KESIMPULAN DAN SARAN}

Dari hasil studi disimpulkan bahwa tingkat adopsi klon karet di tingkat petani pada wilayah-wilayah sampling di Sumatera Selatan telah mencapai 59,2\% dari rata-rata areal tanaman karet, sedangkan tingkat adopsi klon karet unggul pada tahun tanam 2010, telah mencapai $67 \%$ dari rata-rata penanaman karet swadaya. Dari wilayah sampling, tingkat adopsi klon karet unggul yang tertinggi di Sumatera Selatan adalah Kabupaten Muara Enim (83\%), diikuti oleh Kabupaten Banyuasin (81\%), Kabupaten OKU Timur (75\%), Kabupaten Ogan Ilir (73\%) dan Kabupaten OKU Induk (63\%). Sebaliknya tingkat adopsi klon karet unggul yang paling rendah terdapat di Kabupaten Musi Rawas (29\%) dan Kota Lubuk Linggau $(19 \%)$. Jenis klon yang paling banyak dikenal dan diminati oleh petani karet di Sumatera Selatan adalah jenis PB 260 (83\%), diikuti klon GT 1 (48\%), BPM 24 (39\%), IRR 39 (32\%), PR Series (23\%), RRIC 100 (11\%), dan RRIM 600. Klon PB 260 banyak dikenal dan 

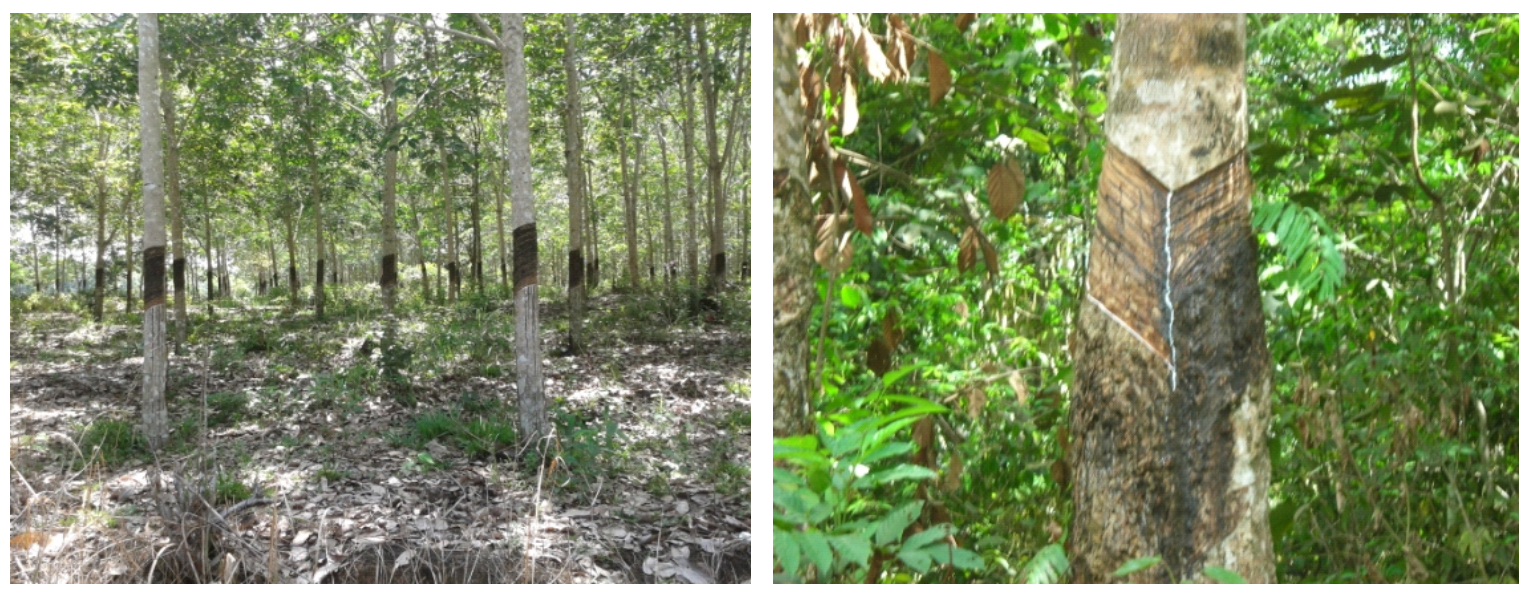

Gambar 4. Kondisi bidang sadap di kebun karet petani di Kabupaten Musi Rawas

Figure 4. Tapping panel condition at smallholder rubber area in Musi Rawas Regency

diminati karena jumlah produksinya tinggi, dan paling banyak dijumpai di penangkar bibit.

Ditinjau dari kondisi usahatani karet rakyat, dan tingkat adopsi klon karet, dapat disimpulkan bahwa Kabupaten Muara Enim, Banyuasin, dan OKU Timur berada pada kategori desa yang sudah maju. Disarankan program peningkatan produktivitas bagi desa-desa yang sudah maju antara lain adalah program pemberian bantuan kredit bagi pembangunan kebun seperti : Mitrabun dan Revitbun. Pendampingan untuk pola kredit harus dilakukan secara berkesinambungan sampai tahap penyadapan dan pengembalian kredit. Meskipun demikian, pengawalan dalam hal penyadapan masih terus perlu dilakukan agar pengetahuan dan keterampilan petani meningkat untuk menghasilkan sadapan yang baik.

Kabupaten OKI, Musi Rawas, dan Lubuk Linggau termasuk kategori desa karet yang belum maju. Disarankan komponen program untuk pengembangan desa-desa karet yang belum maju antara lain: 1) program peningkatan pengetahuan dan motivasi petani untuk segera mengadopsi bahan tanam klon unggul melalui kegiatan demplot kebun peremajaan dan penyuluhan yang intensif. 2) program pembangunan kebun pembibitan untuk menyediakan sarana adopsi secara mudah dan murah melalui pengembangan kelompok pembibit- an dan dengan memperkuat penangkar yang sudah ada di wilayah setempat. Pendampingan harus dilakukan secara intensif sampai petani dapat menghasilkan bibit okulasi unggul dan kegiatan pembibitan dapat terus bergulir.

\section{DAFTAR PUSTAKA}

Dinas Perkebunan Sumatera Selatan. 2008. Statistik Perkebunan Sumatera Selatan Tahun 2008. Dinas Perkebunan Sumatera Selatan, Palembang.

Direktorat Jenderal Perkebunan. 2009. Statistik Perkebunan Indonesia. Karet 2008-2010. Direktorat Jenderal Perkebunan, Jakarta.

Gabungan Perusahaan Karet Indonesia. 2008. Bulletin Karet. Gabungan Perusahaan Karet Indonesia, Jakarta.

Hendratno, S dan M. Supriadi. 2011. Peningkatan produktivitas kebun melalui peremajaan dan penanaman klon karet unggul. Pros. Lok. Karet Nasional, 26 September 2011, Hotel Kartika Chandra, Jakarta.

International Rubber Study Group (IRSG). 2004. Rubber Statistical Bulletin, 58 (12) dan 59 (1) September-October 2004. International Rubber Study Group, Wembley, London. 
International Rubber Study Group (IRSG). 2011. Rubber Statistical Bulletin, 66 (1-3) July - September 2011. International Rubber Study Group, Singapore.
Smith, H.P. 2003. The World Tyre and Rubber Industry and the China Factor: Some Scenario for the Future. Jakarta. 